\title{
Current status of lung transplantation in Korea
}

\author{
Yong Ho Jeong, Dong Kwan Kim, Sehoon Choi
}

Department of Thoracic and Cardiovascular Surgery, Asan Medical Center, University of Ulsan College of Medicine, Seoul, Korea

Contributions: (I) Conception and design: S Choi; (II) Administrative support: S Choi; (III) Provision of study materials and selection of patients: All authors; (IV) Collection and compilation of data: YH Jeong; (V) Data analysis and interpretation: All authors; (VI) Manuscript writing: All authors; (VII) Final approval of manuscript: All authors.

Correspondence to: Sehoon Choi, MD. Department of Thoracic and Cardiovascular Surgery, Asan Medical Center, University of Ulsan College of Medicine, 88 Olympic-ro 43-gil, Songpa-gu, Seoul 05505, Korea. Email: fauntleroy@naver.com.

\begin{abstract}
Since the first transplantation performed in 1963, lung transplantation (LT) has become the primary treatment for end-stage lung disease. In Korea, the first LT was performed in 1996 and the number of transplants remained constant at approximately 10 cases a year until 2010, when the number of LTs increased rapidly. One of the reasons for this increase was the outbreak of humidifier disinfectant-related acute respiratory distress syndrome in 2011, which became an enormous public health concern in Korea. The Korean Network for Organ Sharing (KONOS), which records all deceased-donor LTs performed in Korea, was founded in 2010 following the enactment of the transplantation law. The statistics of LTs in Korea differ significantly from those of the International Society for Heart and Lung Transplantation (ISHLT). First, the common indications for LTs are different; in Korea, idiopathic pulmonary fibrosis (IPF) is the most common reason for LT. Second, the Korean Lung Allocation Score (LAS) considers only the disease severity of the recipient when prioritizing the recipients; thus, nearly half of the LT recipients require extracorporeal membrane oxygenation (ECMO) or mechanical ventilation support prior to transplantation. Third, because of the low rate of usability of the donor lung and paucity of donors, the waiting period for recipients is increasing. Finally, there is a severe mismatch in the number of LTs performed in different regions of Korea. The postoperative 1-, 3-, and 5-year survival rates according to the KONOS registry are $61.8 \%, 52.3 \%$, and $45.3 \%$, respectively. These rates are poorer than those published by the ISHLT, possibly because patients with more severe disease undergo LT in Korea. Therefore, the Korean LAS needs to be adjusted to increase the number of LTs in patients with less severe disease, and to improve the overall survival rate of LT recipients.
\end{abstract}

Keywords: Lung transplantation (LT); Korea; Lung Allocation Score (LAS); post-transplantation survival

Received: 30 May 2020; Accepted: 13 October 2020; Published: 25 February 2022.

doi: $10.21037 /$ ccts-20-110

View this article at: http://dx.doi.org/10.21037/ccts-20-110

\section{History of lung transplantation (LT) in Korea}

The first LT was performed in June 1963 by Hardy of the University of Mississippi (1), and LT has since become the main treatment for end-stage lung disease. The International Society for Heart and Lung Transplantation (ISHLT) reported 4,452 LTs performed in 2017, globally (2). In Korea, the first LT was performed in 1996 (3) at Severance Hospital; the patient underwent a single lung transplant to treat pulmonary fibrosis, but died 82 days later because of infection (3). The number of LTs did not increase significantly thereafter. However, in 2011, the number of LTs increased to 35, which was nearly double the number of cases $(\mathrm{n}=18)$ reported in 2010 (4) (Figure 1). This was due to a national outbreak of acute respiratory distress caused by humidifier disinfectant-associated interstitial lung disease (ILD). In February 2011, several young patients were hospitalized in the intensive care units (ICUs) for respiratory distress with no obvious cause. Following an 


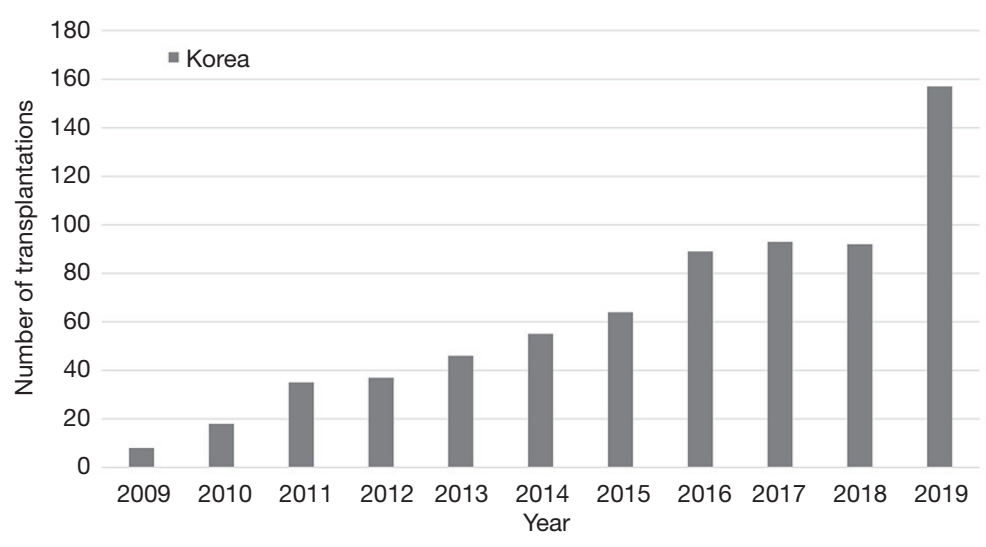

Figure 1 Number of LTs performed in Korea. LT, lung transplantation.

investigation by the Korean Center for Disease Control and Korea Research Group for Respiratory Failure, a humidifier disinfectant was identified as the causative factor. Hong et al. (5) studied 17 patients with humidifier disinfectantinduced acute respiratory distress. Ten patients were admitted to the ICU for mechanical ventilation. Overall, four patients underwent LT, and five of the remaining six patients who did not undergo LT died. Since this incident in 2011, the number of LTs increased rapidly, up to 157 cases a year by 2019 (Figure 1).

The transplantation law was enacted in 1999 by the National Assembly of the Republic of Korea. The Korean Network for Organ Sharing (KONOS) was founded in 2010, following the enactment of the transplantation law, to manage organ donation. Since its foundation, the KONOS manages organ donations from 36 organ procurement organizations, and not only distributes the organs of deceased donors, but also publishes annual statistics of nationwide organ transplantation.

In 2017, the first living-donor lobar LT (LDLLT) was performed at Asan Medical Center (AMC) (6) in a 19-year-old female patient with idiopathic pulmonary artery hypertension who developed progressive heart failure. Her condition deteriorated rapidly, but no deceased donor could be found. LDLLT was performed, although the transplantation law did not allow living-donor lung harvest at the time. The patient continued to remain well 2 years after the surgery. The transplantation law was subsequently amended in December 2018 to allow lung donation from living donors.

\section{Characteristics of LT in Korea}

The indication for LT in Korea differs from that suggested by the ISHLT. According to the 2019 ISHLT LT report, chronic obstructive pulmonary disease is the most common reason $(30.1 \%)$ for LT, and ILD is the second most common reason $(26.1 \%)$. However, the number of ILD patients is increasing rapidly, and ILD was the most common reason for LT globally in 2017 (40.5\%) (2). In Korea, idiopathic pulmonary fibrosis (IPF) was the most common reason for LT (49.9\%), both cumulatively and in 2018 (4) (Table 1).

The proportion of LT recipients who require mechanical ventilation or extracorporeal membrane oxygenation (ECMO) support is very high. In Korea, $46.2 \%$ of the LT recipients were supported by ECMO and/or mechanical ventilation (e.g., status 0) between 2009 and 2018 (Table 1). This is much higher than the proportion reported in the United States of America, which is less than 8\% (7). This is primarily due to the difference in the allocation system. The Lung Allocation Score (LAS), suggested by the United Network for Organ Sharing, considers not only the urgency but also the life expectancy of the recipient after transplantation. LAS was successfully introduced in the United States of America and increased the survival of LT (8). However, in Korea, the LAS is based only on the disease severity of the recipient (Table 2). Consequently, more patients with severe disease on ECMO or ventilator support receive the lungs, which might explain the poor outcome of LT in Korea (9). Studies have suggested revision of the Korean LAS to reduce the proportion of status 0 patients undergoing LT, for better survival (10).

The waiting period for LT recipients is increasing, mainly due to the paucity of donors (Table 3). As seen in Table 4, the number of enlisted recipients has doubled during the last 3 years; however, the number of brain-dead 
Table 1 Demographics of LT recipients from KONOS

\begin{tabular}{|c|c|}
\hline Characteristics & KONOS, n (\%) \\
\hline \multicolumn{2}{|l|}{ Sex } \\
\hline Male & $324(60.3)$ \\
\hline Female & $213(39.7)$ \\
\hline \multicolumn{2}{|l|}{ Age (years) } \\
\hline $1-5$ & $8(1.5)$ \\
\hline $6-10$ & $5(1.0)$ \\
\hline $11-17$ & $15(2.8)$ \\
\hline $18-34$ & $52(9.7)$ \\
\hline $35-49$ & $126(23.5)$ \\
\hline $50-64$ & 275 (51.2) \\
\hline $65-74$ & $55(10.2)$ \\
\hline $75+$ & $1(0.2)$ \\
\hline \multicolumn{2}{|l|}{ Status } \\
\hline 0 & 248 (46.2) \\
\hline 1 & 205 (38.2) \\
\hline 2 & $43(8.0)$ \\
\hline 3 & $40(7.4)$ \\
\hline Others & $1(0.2)$ \\
\hline \multicolumn{2}{|l|}{ Diagnosis } \\
\hline IPF & 268 (49.9) \\
\hline Post-transplant BO & $34(6.3)$ \\
\hline Bronchiectasis & $28(5.2)$ \\
\hline Primary pulmonary hypertension & $18(3.4)$ \\
\hline Lymphangioleiomyomatosis & $14(2.6)$ \\
\hline Emphysema & $5(1.0)$ \\
\hline Eisenmenger syndrome & $3(0.6)$ \\
\hline Asbestosis & $3(0.6)$ \\
\hline Cystic fibrosis & $2(0.4)$ \\
\hline Others & 189 (35.2) \\
\hline
\end{tabular}

LT, lung transplantation; KONOS, Korean Network for Organ Sharing; IPF, idiopathic pulmonary fibrosis; BO, bronchiolitis obliterans. donors remains stagnant. To overcome this shortage, the rate of usage of the lungs must be increased. According to the KONOS registry, Yeo et al. (11) reported that only $12.9 \%$ of brain-dead patients donated their lungs between 2012 and 2016. According to Kotecha et al., the rate of lung usage from brain-dead donors was $22 \%$ in the United States, 32\% in Europe, and 41\% in Australia in 2012, which was more than twice the lung usage rate in Korea (12). This was because only $22.6 \%$ of the donors consented to lung donation, while $35.9 \%$ of the marginal donors were neglected. To minimize this discrepancy, public education and encouragement by clinicians to the potential donors'

Table 2 Korean LAS (9)

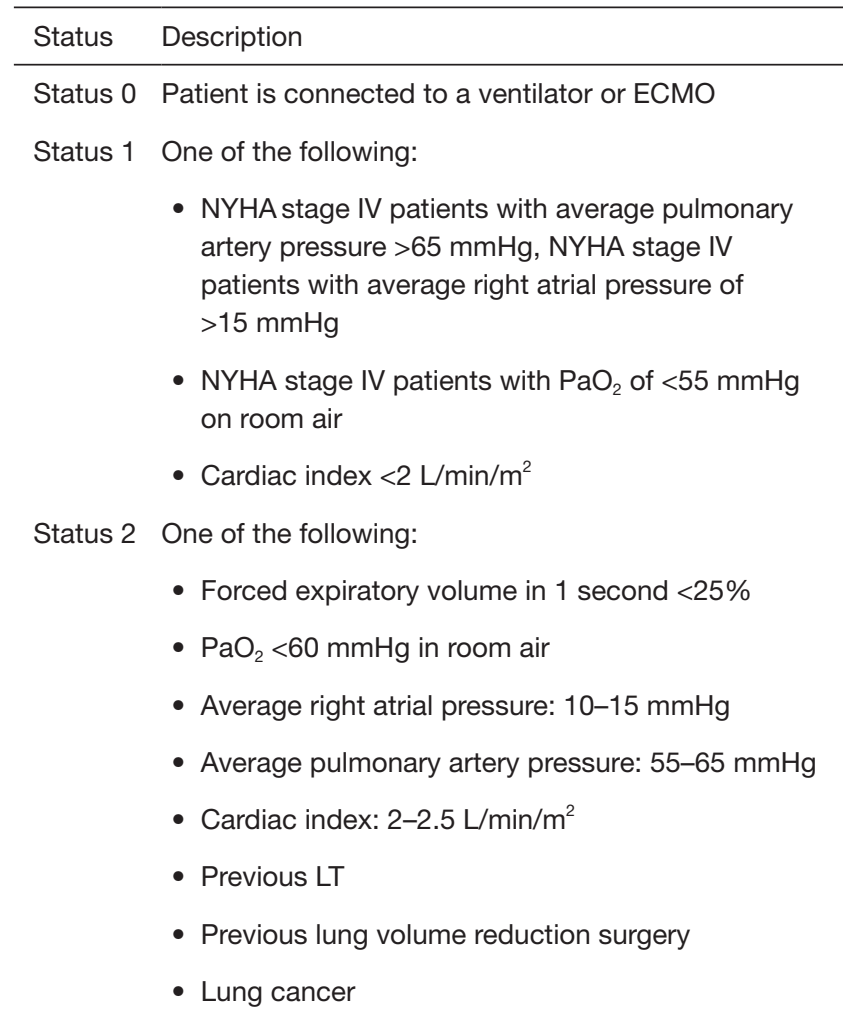

Status 3 Patient requiring a LT with none of the above conditions LAS, Lung Allocation Score; ECMO, extracorporeal membrane oxygenation; NYHA, New York Heart Association; LT, lung transplantation. 
Table 3 Waiting period for LT

\begin{tabular}{|c|c|c|c|c|c|c|c|c|c|c|}
\hline & \multicolumn{10}{|c|}{ Year } \\
\hline KONOS (days) & 84 & 83 & 53 & 102 & 91 & 96 & 118 & 116 & 116 & 147 \\
\hline
\end{tabular}

LT, lung transplantation; KONOS, Korean Network for Organ Sharing.

Table 4 Lung usage and number of enlisted recipients in Korea

\begin{tabular}{|c|c|c|c|c|c|c|c|c|c|c|c|}
\hline & \multicolumn{11}{|c|}{ Year } \\
\hline Number of brain-dead donors & 261 & 268 & 368 & 409 & 416 & 446 & 501 & 573 & 515 & 449 & 450 \\
\hline Lung donors & 8 & 18 & 35 & 37 & 46 & 55 & 64 & 89 & 93 & 92 & 157 \\
\hline Lung usage (\%) & 3.1 & 6.7 & 9.5 & 9.0 & 11.1 & 12.3 & 12.8 & 15.5 & 18.1 & 20.5 & 34.9 \\
\hline
\end{tabular}

${ }^{\dagger}$, Number of enlisted recipients at the end of the year.

Table 5 Locations of LTs performed in Korea

\begin{tabular}{|c|c|c|c|c|c|c|}
\hline & \multicolumn{5}{|c|}{ Year } & Total \\
\hline Total & 55 & 64 & 89 & 93 & 92 & 393 \\
\hline Zone 1 & 50 (90.9\%) & 59 (92.2\%) & 77 (86.5\%) & 77 (82.8\%) & 79 (85.9\%) & 342 (87.0\%) \\
\hline Zone 2 & 0 & 0 & 0 & 0 & 0 & - \\
\hline
\end{tabular}

Zone 1: Seoul, Gyeonggi, and Gangwon provinces, and Jeju Island; zone 2: northern and southern Chungcheong, and northern and southern Jeolla provinces; zone 3: northern and southern Gyeongsang provinces. LT, lung transplantation.

families to donate the lungs is necessary; this might increase the total number of donors and implement a change in criteria. Further, systematic donor management is also necessary to include the marginal lungs for donation (11). Park et al. suggested that proper management of the ICU, a new organ procurement program, and LDLLT could increase the usage rate and the total number of lung donations (13). Furthermore, Yeo et al. (11) reported that lungs from 127 (9.7\%) consenting donors were not used from March 2012 to March 2016 because it did not match with the final recipients. This was because of the recipients' condition being inoperable when the donor lung was available, especially among patients in the ICU. Therefore, maintaining or improving the physical status of the recipients in the ICU is crucial to increase the lung usage rate. Organ procurement programs, including harvesting lungs from patients with circulatory arrest or using ex vivo lung perfusion, could be suggested (14). However, in Korea, no lungs were harvested from patients with circulatory arrest and no study has been conducted using ex vivo lung perfusion for an actual LT. LDLLT is a technique that uses two lower lobes from two healthy donors for transplant to a single recipient. LDLLT could be very helpful for children or young patients who are unable to find matched donor lungs in time.

According to KONOS, Korea is divided into three zones: zone 1 comprises Seoul, Gyeonggi, Gangwon provinces, and Jeju Island; zone 2 comprises northern and southern Chungcheong, and northern and southern Jeolla provinces; and zone 3 comprises northern and southern Gyeongsang provinces. We found a considerable mismatch between the zones in terms of the number of LTs performed (Table 5). 


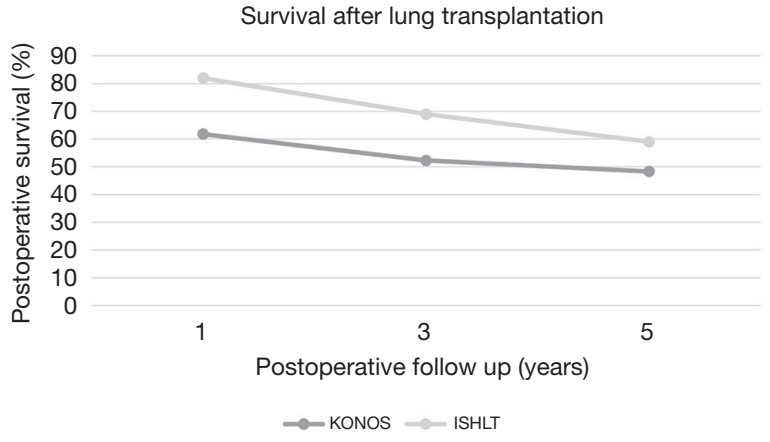

Figure 2 Survival after LT. LT, lung transplantation; KONOS, Korean Network for Organ Sharing; ISHLT, International Society for Heart and Lung Transplantation.

Most of the LTs (87.0\%) were performed in zone 1, which includes Seoul. There are five major centers in Korea: the AMC, Severance Hospital, Samsung Medical Center, Seoul National University Hospital, and Pusan National University Yangsan Hospital. Four of the major centers are located in Seoul, and one is located in Pusan. Thus, four major centers are located in zone 1, one major center is located in zone 3 , and there is no LT center located in zone 2.

\section{Results and survival of LT in Korea}

According to the KONOS transplantation registry, from January 2009 to December 2018, 537 patients underwent LT in Korea (Figure 1). Majority of the recipients were male $(60.3 \%)$, and more than half the recipients were aged between 50 and 64 years (51.2\%) (Table 1). Nearly half of the receivers were at status $0(46.2 \%)$ and $38.2 \%$ were at status 1 (Table 1); a patient is considered to be at status 0 when a ventilation or ECMO is required (Table 2). The most frequent diagnosis in these recipients was IPF, which accounted for $49.9 \%$ of all cases. The waiting period between registration and transplant is shown in Table 3. The KONOS data show a tendency of increasing interval. The number of patients enlisted and lung usage rates from brain-dead donors are shown in Table 4. The lung usage rate increased steadily up to $34.9 \%$ in 2019 according to KONOS.

The survival of LT recipients is shown in Figure 2. The postoperative 1-, 3-, and 5-year survival according to the KONOS registry was $61.8 \%, 52.3 \%$, and $45.3 \%$ respectively; these results are inferior with those of the ISHLT registry (2) (Figure 2).
Few studies have reported the results of LT in Korea. The first study was by Haam et al. in 2008 (15), which reported the results of 18 patients who received lung or heart-LT between July 1996 and October 2007 at Yonsei Severance Hospital. In this study, nine single LTs, eight bilateral LTs, and one heart-LT was performed. Five patients died postoperatively, and the mean survival period of the surviving patients was $18.5 \pm 23.7$ months. Furthermore, the clinical outcome of heart-LT was also published by Yun et al. from a single center study (16) that included 11 patients who underwent heart-LT at AMC between July 2010 and August 2014. Early postoperative mortality occurred in two patients, and late mortality occurred in three patients who survived more than 22 months. The survival rates at 1, 2, and 3 years after the heart-LT were $80 \%, 67 \%$, and $53 \%$, respectively. Jo et al. reported the post-LT survival rates for 60 adult patients, consisting of 51 bilateral LTs and 9 heart-LTs performed in AMC between January 2008 and December 2017, at 1,3 , and 5 years were $75.5 \%, 67.6 \%$, and $61.8 \%$, respectively (17). In addition, the first report using data from the Korean Organ Transplant Registry (KOTRY) was published by Lee et al. in 2018 (18), in which a total of 69 patients were enrolled from five institutions, and the 1 -year survival rate was $60.3 \%$.

\section{Conclusions}

In Korea, LT is characterized by a high rate of critical patients receiving transplantation. The Korean LAS needs to be adjusted to decrease the number of patients with severe disease undergoing LT to improve LT survival.

\section{Acknowledgments}

The authors appreciate KONOS for providing access to the national lung transplantation database and the participating centers and the members of the Lung Transplantation Centers. We would like to thank Editage (www.editage. co.kr) for English language editing.

Funding: None.

\section{Footnote}

Provenance and Peer Review: This article was commissioned by the Guest Editors (Jing Yu Chen and Michael Hsin) for the series "Highlights of the First International Symposium on Lung transplantation, Wuxi, China, 2019" published in Current Challenges in Thoracic Surgery. The article has 
undergone external peer review.

Peer Review File: Available at https://ccts.amegroups.com/ article/view/10.21037/ccts-20-110/prf

Conflicts of Interest: All authors have completed the ICMJE uniform disclosure form (available at https://ccts.amegroups. com/article/view/10.21037/ccts-20-110/coif). The series "Highlights of the First International Symposium on Lung transplantation, Wuxi, China, 2019" was commissioned by the editorial office without any funding or sponsorship. The authors have no other conflicts of interest to declare.

Ethical Statement: The authors are accountable for all aspects of the work in ensuring that questions related to the accuracy or integrity of any part of the work are appropriately investigated and resolved.

Open Access Statement: This is an Open Access article distributed in accordance with the Creative Commons Attribution-NonCommercial-NoDerivs 4.0 International License (CC BY-NC-ND 4.0), which permits the noncommercial replication and distribution of the article with the strict proviso that no changes or edits are made and the original work is properly cited (including links to both the formal publication through the relevant DOI and the license). See: https://creativecommons.org/licenses/by-nc-nd/4.0/.

\section{References}

1. Hardy JD, Webb WR, Dalton ML Jr, et al. Lung homotransplantation in man: report of the initial case. JAMA 1963;186:1065-74.

2. Chambers DC, Cherikh WS, Harhay MO, et al. The International Thoracic Organ Transplant Registry of the International Society for Heart and Lung Transplantation: thirty-sixth adult lung and heart-lung transplantation Report-2019; Focus theme: donor and recipient size match. J Heart Lung Transplant 2019;38:1042-55.

3. Kim HK, Lee DY, Paik HC, et al. Single lung transplantation in pulmonary fibrosis patients. J Korean Soc Transplant 1999;13:165-70.

4. KONOS. 2018 Organ Transplantation Statistics. 2019. Available online: https://www.konos.go.kr/konosis/ common/bizlogic.jsp

5. Hong SB, Kim HJ, Huh JW, et al. A cluster of lung injury associated with home humidifier use: clinical, radiological and pathological description of a new syndrome. Thorax
2014;69:694-702.

6. Choi S, Park SI, Lee GD, et al. The first living-donor lobar lung transplantation in Korea: a case report. J Korean Med Sci 2018;33:e282.

7. Hayanga JWA, Chan EG, Musgrove K, et al. Extracorporeal membrane oxygenation in the perioperative care of the lung transplant patient. Semin Cardiothorac Vasc Anesth 2020;24:45-53.

8. Merlo CA, Weiss ES, Orens JB, et al. Impact of U.S. Lung Allocation Score on survival after lung transplantation. J Heart Lung Transplant 2009;28:769-75.

9. Yu WS, Kim SY, Kim YT, et al. Characteristics of lung allocation and outcomes of lung transplant according to the Korean Urgency Status. Yonsei Med J 2019;60:992-7.

10. Yu WS, Suh JW, Song SH, et al. The lung allocation score could evaluate allocation systems in countries that do not use the score. PLoS One 2019;14:e0214853.

11. Yeo HJ, Yoon SH, Lee SE, et al. Current status and future of lung donation in Korea. J Korean Med Sci 2017;32:1953-8.

12. Kotecha S, Hobson J, Fuller J, et al. Continued successful evolution of extended criteria donor lungs for transplantation. Ann Thorac Surg 2017;104:1702-9.

13. Park SI, Choi S. On improving donor lung usage rate for transplantation. J Korean Med Sci 2017;32:1903-4.

14. Cypel M, Yeung JC, Liu M, et al. Normothermic ex vivo lung perfusion in clinical lung transplantation. $\mathrm{N}$ Engl J Med 2011;364:1431-40.

15. Haam SJ, Lee DY, Paik HC. An overview of lung transplantation in Korea. Transplant Proc 2008;40:2620-2.

16. Yun JK, Choi SH, Park SI, et al. Clinical outcomes of heart-lung transplantation: review of 10 single-center consecutive patients. Korean J Thorac Cardiovasc Surg 2016;49:157-64.

17. Jo KW, Hong SB, Kim DK, et al. Long-term outcomes of adult lung transplantation recipients: a single-center experience in South Korea. Tuberc Respir Dis (Seoul) 2019;82:348-56.

18. Lee JG, Kim SY, Kim YT, et al. First report of the Korean Lung Transplantation Registry. Transplant Proc 2018;50:2759-63.

doi: $10.21037 /$ ccts-20-110

Cite this article as: Jeong YH, Kim DK, Choi S. Current status of lung transplantation in Korea. Curr Chall Thorac Surg 2022;4:4. 